\title{
Patients' satisfaction of health service quality in public hospitals: A PubHosQual analysis
}

\author{
Reham Zuhier Qasim Almomani ${ }^{a^{*}}$, Ruba Risheed Al-Ghdabi ${ }^{\mathrm{b}}$ and Khaled Mohammad Bany- \\ hamdan $^{\mathrm{c}}$
}

\author{
${ }^{a}$ Assistant professor, Business Administration Department, Business Faculty, Amman Arab University, Jordan \\ ${ }^{b}$ Assistant professor, business Administration Department, Amman College for Financial and Managerial Science, Al-Balga Applied Uni- \\ versity, Jordan
}

${ }^{c}$ Associate professor, Business Administration Department, Business Faculty, Amman Arab University, Jordan

\section{CH R O N I C L E}

\section{Article history:}

Received: October 9, 2019

Received in revised format: November 252019

Accepted: December 27, 2019

Available online:

December 27, 2019

Keywords:

Health service quality

Patients' satisfaction

PubHosQual

Public hospitals

Jordan

\section{A B S T R A C T}

\begin{abstract}
Patients' satisfaction has become one of the critical issues for governments all over the world and they are prioritizing to keep their citizens happy. The objective of the current study was to determine the impact of health service quality on patient's satisfaction. The study was applied on public hospitals in Jordan. The participants of this research were physician/doctors working in public hospitals in Jordan, a convenience sample with 400 questionnaires handled to the patients, and 354 questionnaires were valid for statistics. The researchers used the AMOS software version 20 to test the hypothesized structural equation model. Health service quality explained $\% 65.7$ of the variation of patient satisfaction, which was also, illustrated the extent to which the quality of health service had the potential to make a change in the level of patients' satisfaction in public hospitals. Health service quality had a positive effect on patient satisfaction; therefore, researchers pointed out some recommendations for top management and decision-makers at public hospitals.
\end{abstract}

(C) 2020 by the authors; licensee Growing Science, Canada

\section{Introduction}

With the increase in competition appeared in business environment, customers' expectations and requirements are also increasing, leading to a situation where most organizations find it too difficult to retain their customers (Boadi et al., 2019; Farooq et al., 2018; Fatima et al., 2018). Best quality of service is considered as a critical factor which can be used for distinguishing and improving the performance of organization in the era of intensive competition (Farooq et al., 2018; Jamaluddin \& Ruswanti, 2017). Previously, hospitals were evaluating health care services provided to patients based on the opinions of medical, administrative and technical staff. Nowadays, this point of view has been shifted to be based on the opinions of services beneficiaries. As a result, hospitals' focus becomes more on aspects related to patients to improve their satisfaction primarily and before anything else (Choi et al., 2005). Patient satisfaction may be considered as a key marker for the healthcare quality, and this internationally accepted factor needs to be studied repeatedly for the smooth functioning of the healthcare organizations (Cohen et al., 2017). Patients' satisfaction regarding healthcare quality has become one of the critical issues for governments all over the world and they are trying to keep their citizens happy (Ampah \& Ali, 2019). The patient's opinion has become more important in the improvement of a health care system (Manzoor et al., 2019). Patients' feedback and their perceptions are important requirements for many accreditations and evaluating programs for hospital services (Abbasi-Moghaddam et al., 2019). Healthcare organizations are shifting toward a market-oriented strategy and devel- 
oped efficient programs of quality improvement by adopting patient satisfaction to be the benchmark of organizational performance (Asif et al., 2019; Huerta et al., 2016; Bahadori et al., 2016). Patient satisfaction has long been considered as an essential component of people-centered care, and an important factor for health care quality (Hemadeh et al., 2019; Ogaji, 2017; Wei et al., 2015; Louw et al., 2017). Healthcare quality is one of the most critical things in the life of humans. Best health care services help in maintaining and sustaining a healthy human capital which plays a big role for the development of the country (Salaria \& Shakeel, 2019). Healthcare quality is to provide the right healthcare services to get the right results' (Mosadeghrad, 2012). Previous researches have provided several models of healthcare service quality that is linked to better institutional performance (Mohamed \& Azizan, 2015). In spite of the difficulties related to the use of SERVQUAL, which have been mentioned in many kinds of research, it sounds that most studies in the area of measuring the health services have used it. These difficulties are due to the lack of clarity of the patients' expectations, and the uncertainty of the scale over time, in addition to the multiple dimensions of the scale. SERVQUAL also faced other criticisms, including that the evaluation of service quality, which is based on what the patient is expecting and what had already been obtained, is lacking scientific evidence and was not based on scientific theory.

Moreover, the expectations of such measure could bear more than one explanation and they may indicate to the desires or level of service that patients hope to receive or the appropriateness of the service from the patient's point of view, and these expectations may be the ideal criteria to obtain the service. Also, the researchers report that the SERVQUAL measure focuses on the service delivery process rather than on the quality of service itself (Ladhari, 2008). Aagja and Garg (2010) also concluded that SERVQUAL is not appropriate. Therefore, the researchers used another measure, PUbHOSQUAL, where it was verified for its reliability and stability. The current study showed that the proposed measure is more efficient than its predecessor in measuring the quality of health services in public hospitals.

By referring to the theoretical literature, it is noted that most of the studies have used SERVQUAL scale in evaluating the quality of health services provided to patients in different health institutions. Since the current study is aiming to investigate the impact of health services quality dimensions in public hospitals, it adopted another scale designed specifically to evaluate the quality of health services in public hospitals, which is PUbHOSQUAL, this scale was designed by Aagja and Garg (2010), and includes five dimensions of health services quality in public hospitals: "admission, medical service, overall service, hospital discharge process, and social responsibility".

The researchers pointed out what distinguishes this scale (PUbHOSQUAL) from the other one applied in several previous studies (SERVQUAL). It is more suitable for measuring the quality of health services in public hospitals where it can be used as a diagnostic tool through which to identify the strong points that need to be more enhanced and identifying weakness points in service aspects that require modifications in order to improve the quality of services in these public hospitals. Therefore, the current study can be considered as an added value to the literature, as it dealt with the health services quality from another angle. In practice, the importance of the study is reflected on decision-makers in ministries of health as public hospitals are affiliated to them. As mentioned earlier, the study shows what are the points that need to be improved and draws the attention of hospital administrations to reconsider some aspects of services provided to patients in order to improve the level of supportive services to public hospitals and enable them to achieve their goals efficiently in serving citizens, especially, as they are the largest segment whose are treated in public hospitals. So, this study aims to investigate the impact of health service quality on patients' satisfaction in public hospitals using a more acceptable, appropriate and reliable scale than the other scales used in previous studies, (Aagja \& Garg, 2010). Of course, using a different PUbHOSQUAL scale in evaluating the quality of public hospitals entails focusing on other variables: patient admission, medical service, supportive services, hospital discharge, and hospitals social responsibility.

\section{Theoretical framework and hypotheses development}

\subsection{Patient's Satisfaction}

Patient satisfaction is the patient's perception of care compared with the care expected (Farahani et al., 2014). Patients' perceptions of health services quality provided to them are one of the most important means of evaluating and improving the level of services. Consequently, this concept has been studied in many kinds of studies as a dependent variable, assuming an increase or decrease according to the degree of independent variables influence represented by the dimensions of the health services quality. Researchers usually pay their attention, to the concept of customer's satisfaction in general and patient satisfaction in particular, as a result of comparing the experience of the recipient with his expectations. Initial expectations are the main determinant of satisfaction, and if the perceived quality of service is below expectations, the result will inevitably be dissatisfaction with the service (Tam, 2007). Kotler (2014) defined satisfaction is the feeling of happiness because one has something or has achieved something of value. According to Mulisa et al., (2017), Patient satisfaction is a set of attitudes and perceptions of patients towards health services. Manzoor et al. (2019) defined Patient satisfaction as "the state of pleasure or happiness that the patients experience while using a health service". The study of Naik et al. (2010) showed that the patient's satisfaction is the degree of congruence between the expectations of the client and the perceived performance of the service provided to them. Zineldin (2006) argued that patient satisfaction could be measured by aggregating sub-scores of characteristics associated with an experience of receiving health care. While, the definition of Oliver (1981), in the study of Badri et 
al. (2009), indicated that patient satisfaction is a psychological condition that arose as a result of an emotional response to the experience of the health service in light of his/her prior impressions about this service. Zineldin (2006) defined patient's satisfaction as an assessment of the extent to which the health service met the patient's expectations and preferences. Zineldin (2006) added that according to psychological theories, a patient's assessment of particular situations is associated with personal emotions and with a mismatch between desires and outputs as well as individual preferences and social comparisons. Naidu (2009) also defined patient satisfaction as an assessment of health care dimensions; it can be predicted by factors associated with such care, like empathy, reliability and responsiveness. It can also be evaluated through medical procedures, the availability and continuity of services, patient's confidence in the service level provided to him/her, and the efficiency in providing the service. In terms of evaluating patient's satisfaction, the study of Atinga et al. (2011) used One statement to make such evaluation, which embodied in asking patients: "Are you satisfied with the level of services provided in the hospital?". As for Kang and James (2004) they used the following statements to assess patient's satisfaction: "The service I received was not as what I expected", "I am satisfied with my decision to use this service", "Using this service was for me a good experience", "the experience of this service, for me, will not be repeated in this place".

\subsection{Concept of Health Service Quality}

Researchers in many countries have been interested in studying the quality of health services provided to patients in health care institutions for several reasons, one of the most important is the possibility of using the results in evaluating the quality of health services in comparing health care programs and systems, or in order to identify the services that should be changed or modified to increase patient's satisfaction of these services (Badri et al., 2009). It can be said that most of the service quality definitions in the literature were based on the definition of Parasuraman et al. (1988) who defined the quality of service as the gap between the customers' expectations about the service and their impression after having the experience of receiving such service. In the context of the health service quality, the two approaches through which this term can be understood are Professional Medical approach, Professional Administrative approach. The quality of health service is defined according to the medical approach as providing the best medical services for patients according to the latest worldwide developments and scientific techniques and experiences. As for the professional administrative approach, it reflects how efficient resources available at the hospital are fully utilized to provide outstanding services to patients. Finally, quality of service can be defined from, the patients' point of view, as a result, obtained to meet his / her therapeutic needs in line with his/ her expectations (Saghirou, 2012). WHO has also defined the quality of health services by three pillars: efficiency, effectiveness, and social acceptance of services delivered, by focusing on professional ethics and the consequences of these services for patients that can be measured by indicators such as mortality and disease prevalence (Aagja \& Garg, 2010).

Several measures have been developed by researchers to assess the quality of services and have been used in many sectors. Among these measures, Saghirou (2012) referred to the complaint measure based on the judgment of health service quality through the number of complaints from patients; as well as the value measure, which depends on the distinction between the benefit obtained from the service and the cost of obtaining such service. Saghirou (2012) added the measure of the gap (Servqual), and the actual service performance measure (Servperf). In Bahar and Al-Jady (2019) research, they added another measure to the four mentioned in Saghirou (2012) study which is satisfaction measure; it is one of the commonly used measures to evaluate patient's satisfaction after receiving service, to figure out the strengths or any weaknesses. In this regard, the Aagja and Garg (2010) study referred to several other measures: the European measure developed by Gronroos (1984), and the American measure developed by Parasuraman et al. (1988) known as the Servqual scale, as well as the three-dimensional scale developed by Rust and Oliver (1994). According to the researchers, the European standard depends on two dimensions: functional quality and technical quality. As for the American standard, it uses five dimensions in assessing service quality as follow: tangibility, empathy, assurance, reliability, and responsiveness. In contrast, the three-dimensional model focuses on product quality and the service provided to customers. The following are the main models used to measure the quality of services.

Javed and Ilyas (2018) study was to investigate the impact of patients' expectations from healthcare service quality on their satisfaction with nursing in public and private hospitals in Pakistan; they adopted five dimensions in their research namely; empathy, responsiveness, tangibility, reliability and assurance. Kamal and Fateh (2019) study aimed to identify employees' safety and security systems in healthcare institutions and their contribution to developing health service quality from a service provider point of view; they agreed with Javed and Ilyas (2018) in adopting the same five dimensions to achieve their study's goal. In the same context, Yousapronpaiboon and William (2013) and Munnukka et al. (2013) used the same dimensions to evaluate the quality of health service. In a study conducted by Al-Tit (2015) to identify the quality of services, dimensions of tangibility, reliability, responsiveness, affirmation and empathy were used. These dimensions were also used in the Abuosi and Atinga (2013) study to examine the quality of health service in public hospitals in Ghana. In another study by Al-Borie et al. (2013) on a sample of patients in public and private hospitals in Saudi Arabia, the following dimensions were used in appraising the quality of health services: tangibility, reliability, response, safety, and empathy. They are the same dimensions used in the Jabnoun and AL Rasasi (2005) study to identify the quality of health services in a sample of patients in six hospitals in the UAE. While Al-Hawary et al. (2011) studied another set of dimensions in their research; access to services, location, health care, communications, equipment, facilities, as well as prices to assess the quality of service at King Abdullah II Teaching Hospital. Al-Zubaidi and Hassan (2010) used the following dimensions: responsiveness, tangibility, reliability, 
safety, and empathy to assess the quality of governmental hospitals in Baghdad. Diab study (2012) in Jordanian public hospitals also examined the same dimensions as Al-Zubaidi and Hassan (2010): reliability, responsiveness, safety, empathy, and tangibility. The Abu Shukr study (2012), conducted on a sample of private hospitals in Amman, and assessed the quality of health services from the perspective of staff and patients using the following dimensions: quality of health services, quality of administrative services, and quality of accommodation services, which are derived from the dimensions adopted in Gaps scale.

The current study adopts the scale developed by Aagja and Garg (2010) to measure the perceived quality of service in public hospitals, which is the PubHosQual, as mentioned earlier, it has a high degree of reliability. The study adopted this scale, according to the criticism of researchers to the scale Servqual; thus PubHosQual is more suitable for use, especially since the current study is interested in measuring the quality of service in public hospitals. Pai and Chary (2013) pointed out the importance of using PubHosQual in assessing the quality of health services from the patients' point of view because it is more appropriate because the study is conducted in public hospitals. Among the studies that have adopted the PubHosQual scale is the Amin and Nasharuddin (2013) study, which was conducted to identify the impact of the quality of health services provided on patient satisfaction in a sample of public and private hospitals in Malaysia. By referring to Naidu (2009), researchers found that Woodside (1989) study is also used the following dimensions in measuring the quality of service: hospital admission, hospital discharge, quality of health care received, as well as other factors such as nutrition quality, technical quality, And the level of room service in the hospital. Atinga et al. (2011) addressed the importance of using the after-check-in and out of patients to and from the hospital in measuring the quality of health services according to their impact on patient's satisfaction. PubHosQual scale, as it is adopted in the current study, consists of the following dimensions:

- Patient Admission: Patient admission is related to all procedures, processes and services that start from the moment the patient arrives at the hospital, including registration procedures, treatment of patients, and the ability of the hospital to deal with emergencies and provide first aid (Aagja \& Garg, 2010).

- Medical Service: Medical service is about having medical solutions for patients' problems; it is embodied in many things such as the hospital's focus on time for delivering health service so that it is on time without delay, the patient should be informed of the date of service delivery, providing assistance and personal attention to patients by medical staff, understanding the personal needs of patients, allocate enough time to stay with patients and pay the needed attention all over the week (24/7). As for patients, they should feel safe when dealing with the medical and administrative staff in the hospital; cleared information must be given to patients when needed, hospital's focus on safety in general and everywhere at hospital's facilities, and rapid response to patients when needed.

- Overall Services: Supportive services refer to the result of several factors that measure the degree of hospital's caring and commitment to other aspects in addition to the health service itself. These factors include readiness, aesthetics and cleanliness of the hospital facilities, health education, and provide a common sense and a sincere desire to help patients quickly and respond to their needs as they are the priority for the hospital (Aagja and Garg,2010).

- Hospital Discharge: Although studies used many indicators to evaluate health service quality, nonetheless, a little number of researches have studied hospital discharge indicator, but unfortunately, it did not have the researchers' attention (Badri et al., 2009). This concept is referring to all procedures, processes and activities related to discharging patients from the hospital in terms of the speed of performing this procedure and provide the patient with sufficient and adequate information and advice to follow up after leaving from the hospital such as taking medications, proper nutrition, what types of foods are allowed; all of this will be reflected on the patient's satisfaction.

- Hospitals Social Responsibility: Social responsibility refers to the social, ethical and legal treatment by the organization towards all stakeholders (Dahlsrud, 2008). Yuen and Thai (2015) is one of the studies that used the CSR indicator in evaluating quality of the service. For the current study, this dimension was measured by focusing on the equal treatment of all patients without discrimination, providing services that cover the patient's medical needs at a reasonable cost, as well as the sense of responsibility of all hospital's staff, which improves the level of patient satisfaction.

\subsection{The Relationship between Quality of Health Services and Patient Satisfaction}

Farraj (2009) conducted a study in educational hospitals in Syria and found a relationship between the dimensions of health service quality and patient satisfaction. Walah (2012) had another study in the Algerian hospitals; his study was to identify the role of health services quality in patient's satisfaction. Improving patient health care has become a priority for all health care service institutions to attain a high level of patient satisfaction (Manzoor et al., 2019). In Kuwait, Bu Abbas (2010) study verified the nature of the relationship between these two variables and the results of the study confirmed the existence of a significant impact of services' quality, in both the public and private hospitals, on patients' satisfaction, but the level of patients' satisfaction in the private hospitals is higher than in the public ones. Chahal and Mehta (2013) concluded that healthcare service quality affected patient satisfaction. Their results reveal that patient satisfaction is a multidimensional construct comprised of four dimensions, namely: physical maintenance, physician care, nursing care and internal facilities. Study conducted in Nigeria by Ikediashi et al. (2015) reveals that, Nigerian public hospitals used the Servqual scale dimensions represented by tangibility, reliability, assurance, response and empathy to evaluate a range of services relates to hospital and patients, by which the hospital is relying on another outsource parties to provide such services like food service, maintenance, cleaning, 
security, environmental management and waste management. A study was done by (Asif et al., 2019) on how healthcare service quality affects patient satisfaction. The results of the study showed a significant and positive impact of medical quality on patient satisfaction. A study conducted in Pakistan reveals that healthcare service quality affected patient satisfaction. Their result indicated an impact of healthcare services on patient satisfaction (Shabbir et al., 2016). Amin and Nasharuddin (2013) study verified the relationship between health services quality and patient's satisfaction by examining the same dimensions used in the current study and found a statistically significant effect of patient admission, medical service, supportive services, hospital discharge, and social responsibility on patient's satisfaction. While the study of Vinagre and Neves (2008) examined Servqualscale dimensions to identify the main influencing factors on patient's satisfaction in public health centres in Portugal and found that there is a positive relationship between health services quality dimensions (empathy, responsiveness, tangibility, reliability and assurance) and patient's satisfaction. As forElleuch (2008), he studied the same dimensions conducted in Vinagre and Neves (2008) study in the purpose of verifying the relationship between health service quality and patient's satisfaction in small private clinics in an area west Japan and showed that the dimensions of health services quality are pre-determinants of patient's satisfaction. Based on the above literature, the study hypotheses may be formulated as:

\section{H1: Health service quality has a significantly positive effect on patients' satisfaction.}

\section{More specifically:}

$\mathrm{H}_{11}$ : Patient Admission has a significantly positive effect on Patients' satisfaction.

$\mathrm{H}_{12}$ : Medical Service has a significantly positive effect on Patients' satisfaction.

$\mathrm{H}_{13}$ : Overall Services has a significantly positive effect on Patients' satisfaction.

$\mathrm{H}_{14}$ : Hospital Discharge has a significantly positive effect on Patients' satisfaction.

$\mathrm{H}_{15}$ : Hospitals Social Responsibility has a significantly positive effect on Patients' satisfaction.

\section{Hypothesized model}

The research model, as summarized in Fig. 1. explores the impact of the quality of health services dimensions on patient satisfaction. Health services quality consists of (Registration of Patient Admission, Medical Services, Support Services, Registration of Patient discharge, and Social responsibility) and the constructs of patient satisfaction consist of six items.

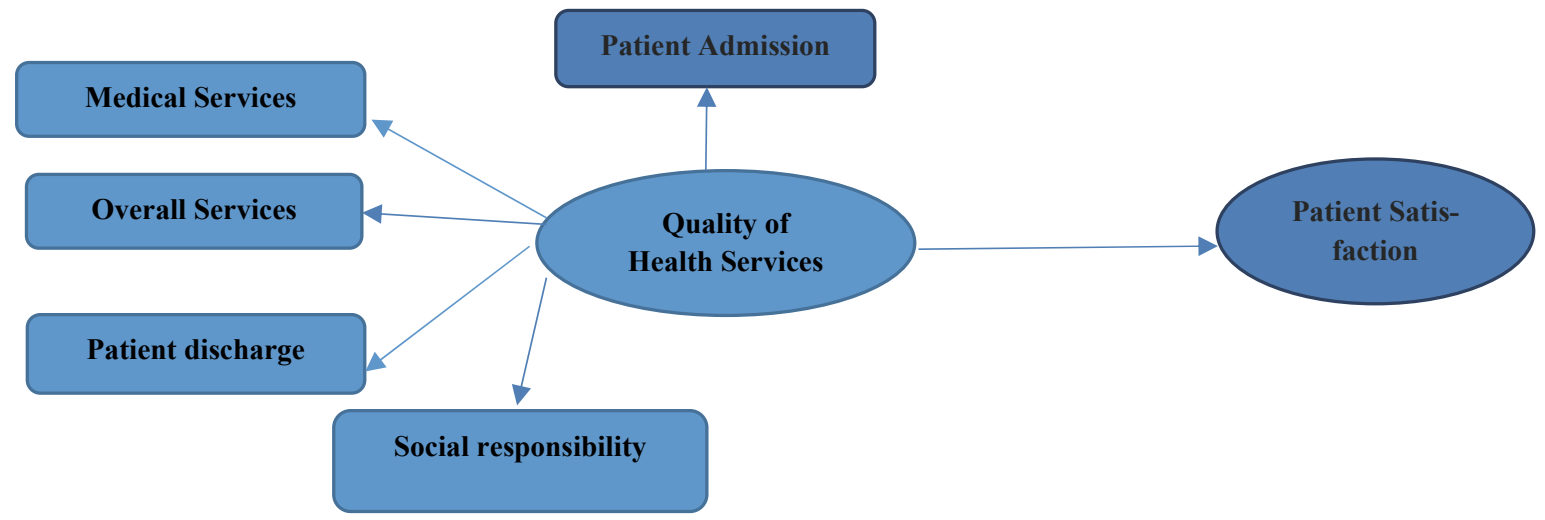

Fig. 1. Conceptual frame work

\section{Methodology}

\subsection{Population and sampling}

The participants of this research were physician/doctors working in public hospitals located in the capital of Jordan, namely; Al-Bashir Hospital, Prince Hamza Hospital, Prince Hamza Hospital, Jameel Al Totangi Hospital. In this research, a selfadministrated questionnaire was used to collect the data; it was conducted from early April to June 2019. A convenience sample with 400 questionnaires handled to the patients, and only 376 filled and returned, out of which 22 questionnaires had to be excluded, and 354 questionnaires were valid for statistics. Females make (170 respondents) $48.03 \%$ of the patients on the other hand; male respondents represented (184 respondents) $51.97 \%$ of the sample. The largest group of respondents (147 respondents) $41.53 \%$ were aged above 50. The next largest group (78 respondents) $22.03 \%$ were aged $40-$ from 30 to 40 years. The next largest group of respondents ( 72 respondent) $20.34 \%$ from 40 to 50 years and smaller groups of respondents were aged less than 30 (57 respondents) $16.1 \%$. About educational level, people with the only diploma and below make (93 
respondent) $26.27 \%$ of the patients. The bachelor degrees Holders were the largest group of respondents make (207 respondents) (58.47\%). Finally, holders of post-graduate degrees make (54 respondents) $15.26 \%$ of the patients.

Table 1

Sample characteristics

\begin{tabular}{|c|c|c|}
\hline 1-Gender & Frequency & Percent $(\%)$ \\
\hline Male & 184 & $51.97 \%$ \\
\hline Female & 170 & $48.03 \%$ \\
\hline \multicolumn{3}{|l|}{ 2- Age } \\
\hline below 30 yrs. & 57 & $16.1 \%$. \\
\hline From 30 yrs. - to 40 yrs. & 78 & $22.03 \%$ \\
\hline From 40 yrs. - to 50 yrs. & 72 & $20.34 \%$ \\
\hline Above 50 & 147 & $41.53 \%$ \\
\hline \multicolumn{3}{|l|}{ 3- Education Level } \\
\hline Diploma Degree and below & 93 & $26.27 \%$ \\
\hline Bachelor Degree & 207 & $58.47 \%$ \\
\hline Post Graduate studies & 54 & $15.26 \%$ \\
\hline
\end{tabular}

\subsection{Instruments}

The questionnaires for the present study contained two variables and were developed by using measurement scales adopted from prior studies. Modifications were made to suit the population of the study. These variables are including health care service quality and patient satisfaction. Health care service quality adapted from Aagja and Garg (2010), and consisted of five dimensions which are patient admission included 4 items, the sample item was "This hospital provides a quick patients' admission service", medical services included 4 items, the sample item was "Doctors at this hospital have an adequate knowledge and experiences", overall services included 9 items, the sample item was "This hospital has comfortable and attractive facilities ", patient discharge included 4 items, the sample item was "This hospital provides a quick procedures when discharge", and Social responsibility included 3 items, the sample item was "Hospital's staff treats all patients fairly and equitably". Patient satisfaction included 6 items adapted from Soomro et al., (2018). The sample item was "I am satisfied with the treatment provided in this hospital". Measurements were anchored using Five-point Likert scale, where "5" refers to "strongly agree", and "1" describes "strongly disagree".

\section{Statistical Analysis}

\subsection{Reliability test}

The reliability of the study tool is intended to be stable, reliable and predictable. A research tool can be considered to be reliable if applied more than once in similar circumstances (Ary et al., 2002); The Cronbach Alpha, internal consistency test, was used to measure the consistency of the respondents' answers to all the questions in the scale. Its high value indicates the degree of high stability and ranges between ( 0 and 1) and its value is acceptable at (60\%) and above (Hair et al., 2006). Therefore, the reliability scores of the constructs of the research instrument are as shown in Table 2.

Table 2

Cronbach Alpha results

\begin{tabular}{ccc}
\hline Dimension & Number of Items & Cronbach Alpha (Items number) \\
\hline Quality of Health Services & 24 & .80 \\
Patient Admission & 4 & .83 \\
Medical Services & 4 & .78 \\
Overall Services & 9 & .75 \\
Patient discharge & 4 & .84 \\
Social responsibility & 3 & .76 \\
Patients satisfaction & 6 & .73 \\
\hline
\end{tabular}

\subsection{Exploratory Factor analysis}

The researchers started with exploratory factor analysis (EFA) to validate the items and the proposed Five-dimensionality of health service quality scale. Factor analysis using varimax rotation and principal axis factoring was conducted on 24 scale items. As a rule of thumb, items with factor loadings $(<0.5)$ are dropped. The exploratory factor analysis resulted in a grouping of 24 items under five dimensions which had an eigenvalue greater than one, confirming Quality of Health Services as a fivedimensional construct. All items had recorded significant loading and communality values $(>.5)$ in the respective dimensions same thing the patient satisfaction confirming with one dimension with six items. 
In this study, the validation procedures for the instrument followed the method of confirmatory factor analysis (CFA) adopted by Byrne (2010) and Kline (2011). The second-order confirmatory factor model was used to test the construct validity by using the maximum likelihood method. The results consistently supported the factor structure for two constructs. The confirmatory factor analysis technique is based on the comparison of the variance-covariance matrix obtained from the sample to the one obtained from the model. The technique is fairly sensitive to sample size, and it is suggested to have several cases per free parameter (Bollen, 1989).

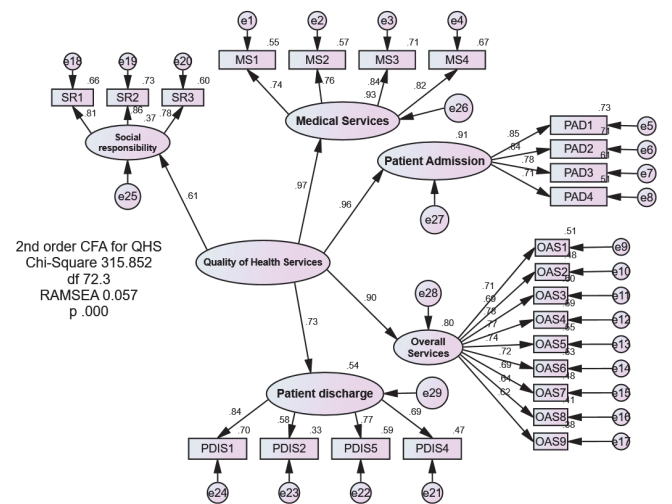

Fig. 2. The second-order CFA Quality of Health Services(QHS)

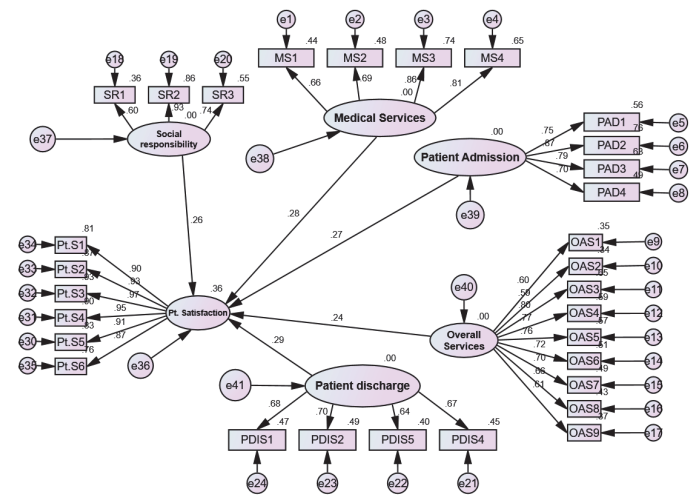

Fig. 3. Full Structure Equation Modeling (QHS dimensions - Pt. Satisfaction)

Table 3

Summary of Fit Statistic Indexes for the CFA Models

\begin{tabular}{cccccccc}
\hline Models & $\mathrm{X} 2$ & $\mathrm{df}$ & $\mathrm{P}$ & Cmindf & RMSEA & CFI & P/Estimates \\
\hline QHS & 315.852 & 72.3 & .000 & 4.368 & 0.057 & 0.905 & $(.62-.97)$ \\
\hline \multicolumn{7}{c}{ N.B: All loadings were statistically significant at an alpha level of $\mathrm{p}=.05$} &
\end{tabular}

\subsection{Final Quality of health service Dimensions - Patient satisfaction Model}

The researchers used the AMOS software version 20 to test the hypothesized structural equation model, as shown in Figs. 23. For each of the dimensions of the Quality of Health service (QHS) and patient satisfaction, the indicator of the variables was the respective dimensions (factors) as determined by the confirmatory factor analyses. Model-fit refers to the degree to which the SEM fits the sample data. The commonly used model-fit criteria are the chi-square (x2), goodness of fit index (GFI), adjusted goodness of fit index (AGFI), comparative fit index (CFI), and also the Root Mean Square Error of Approximation (RMSEA) (Schumacker \& Lomax, 1996)

Table 4

Summary of Fit Statistic Indexes for the Full Structure Equation Modeling

\begin{tabular}{cccccccc} 
Models & $\mathrm{X} 2$ & $\mathrm{df}$ & $\mathrm{P}$ & $\mathrm{Cmindf}$ & $\mathrm{RMSEA}$ & $\mathrm{CFI}$ & $\mathrm{P} /$ Estimates \\
\hline $\begin{array}{l}\text { QHS dimensions - } \\
\text { Patient Satisfaction }\end{array}$ & 562.34 & 148.82 & .001 & 3.778 & 0.0602 & 0.916 & $(.60-.90)$ \\
\hline
\end{tabular}

As shown in Table 4, regarding the information of goodness of fit supporting the model adequacy, statistics confirm the recommended values of a satisfactory model fit to data. The norm-chi-square (Cmin/df) is below 5 (Bollen, 1989; Browne and Cudeck, 1993), the RMSEA <.08, and the CFI \& TLI > .9 (Browne \& Cudeck, 1993; Byrne, 2010) which are acceptable. The parameter loadings as shown in the model all are statistically significant and practically reasonable, coefficients of loading came between .60 to .90 as recommended by Byrne (2010) to be above 0.5 . The relationships between the main two variables (QHSdimensions (5 dimensions) and Patient satisfaction) are considered to be significant, which is indicated by the values of critical ratio (CR) of each of the inter-variable relationships (Byrne, 2010), which are greater than 1.96 (the absolute value), at a significance level less of $\alpha=0.05$. Also, it is shown in the model the evidence of the direct relationships between the constructs of the model. It is shown from the analysis that: QHS dimensions directly influence on Patient satisfaction as following results (Medical Services impact on Pt. satisfaction $=0.28$. Social responsibility impact on Pt. satisfaction $=0.26$. Patient Admission impact on Pt. Satisfaction $=0.27$. Overall Services impact on Pt. Satisfaction $=0.24$. Patient discharge impact on Pt. satisfaction $=0.29$ ). All estimates are statistically significant and logically reasonable, and their values are of an acceptable standard for evidence of direct and indirect effects (.2) (Byrne, 2010). 


\section{Discussion and Conclusions}

The main objective of the current study was to determine the impact of health service quality on patient satisfaction. This study has been applied on public hospitals in Jordan. Four public hospitals located in the capital of Jordan were chosen, namely; Al-Bashir Hospital, Prince Hamza Hospital, Prince Hamza Hospital, Jameel Al Totangi Hospital, to evaluate the quality level of health service and, to determine the level of patient satisfaction. The Adjusted R2 result was (\%65.7), which means that the dimensions of health service quality have explained of $(\% 65.7)$ from the variation of patient satisfaction, which is also, illustrated the extent to which the quality of health service has the potential to make a change in the level of patients' satisfaction in public hospitals. Another result could be concluded here; that there are other factors with a rate of (\%34.3) were affecting patient satisfaction did not address in this study. After using multiple regression analysis and through digital results, it was found that there was a statistically significant effect of health service quality dimensions on patient satisfaction in public hospitals; this result is consistent with other studies' findings such as the study of Manzoor et al. (2019), Amin and Nasharuddin (2013), Chahal and Mehta (2013), Wala (2011), Ikediashi et al. (2015), Bou Abbas (2010), Asif et al., (2019), Farraj (2009), Elleuch (2008), Shabbir et al., (2016), Vinagre and Neves (2008) and Zineldin (2006). Although studies differed in the nomenclature of dimensions, but they had some common factors concluded that health service quality is considered as one of the determining factors of patient's satisfaction and the statistical impact of health service quality on patient satisfaction is resulted only from three dimensions which are: (medical service, supportive services and social responsibility). This is an indicator of the patients' interest in the dimensions related only to the core medical service, where they pay medium attention to the physical, formal and perfection aspects of the service. The patient-focused on aspects of the service quality that are achieving healing such as the skills and experiences of the doctor as well as the medical equipment which support doctors and nurses work, while the aesthetic aspects of the building and facilities were not the focus of attention as any patient in any other hospital. A good health care service performed by the Hospital has an impact on patient satisfaction. So, when hospitals satisfy their patients, the services of the Hospital will be trusted by the patients to cure their illness, and of course it will have a positive effect on patient satisfaction, and in return on the image of the hospital. Reaching the best health care quality is the objective of all healthcare organizations worldwide (AlRyalat et al., 2019). To achieve health service quality, attention must be given to all aspects of health care quality. The patient's satisfaction is represented by obtaining this service when needed, seeing doctor from time to time, doing necessary procedures and continuous tests, the existence of the desire to provide patients with required assistance, the attention paid by hospital's staff to the patients, and understand the personal needs of patients; all of these factors will reflect on the patient's sense of safety when being treated by medical staff in the hospital which in turn will be reflected on patient satisfaction. As mentioned previously, patient satisfaction is a psychological condition that arose as a result of an emotional response to the experience of health service received, and this finding is agreed with the study Amin and Nasharuddin (2013), while Zineldin (2006) stated that there is an impact of operations' quality on patient satisfaction, as the operations' quality reflects the functional quality by measuring how health care activities are implemented.

\section{Recommendations}

Health service is the primary need of human being. This research has the potential to help Managers and decision-makers of the public hospitals in Jordan, to solve increasing problems relating to health services in Jordan, especially in rural areas. Health service quality has a positive effect on patient satisfaction; therefore, researchers pointed out the number of recommendations for top management and decision-makers at public hospitals, so health care institution should insert the patient's satisfaction in its strategic goals list because patients' satisfaction can identify particular enhancements. The population is increasing dramatically, government should also increase the budget specified to the health sector, so they can increase the number of administrative staff and expand their buildings of public hospitals, which in turn will reduce the pressure on hospitals, and reduce waiting time in clinics and ERs, and this definitely resulted in increased patient satisfaction. Secondly, facilitate procedures for patients coming from outside the country in terms of facilitating the obtaining entry visa and getting special treatment at the airport until their arrival of the patient to the hospital. Thirdly, activate recruitment of multidisciplinary, experienced and qualified staff to prevent citizens from travelling to neighboring countries for therapeutic goals. The fourth point is to activate the role of quality assurance department in public hospital to contain an adequate number of developed equipment and technologies that facilitate the work of specialized administrative staff to keep following up the complaints of patients quickly and clearly. The fifth one is to activate the role of research and development department through holding conferences and workshops in and outside the country which increases and exchanges experiences and knowledge of the hospital's staff. Another recommended point is to increase the awareness of administrative staff as their occupation is humane and they are not working for for-profit companies. Public hospitals should also invest more in advertising campaigns to increase the patients' national sense to get the treatment inside their country.

\section{References}

Aagja, J., \& Garg, R. (2010). Measuring perceived service quality for public hospitals (PubHosQual) in the Indian context. International Journal of Pharmaceutical and Healthcare Marketing, 4(1), 60-83.

Abbasi-Moghaddam, M. A., Zarei, E., Bagherzadeh, R., Dargahi, H., \& Farrokhi, P. (2019). Evaluation of service quality from patients' viewpoint. BMC Health Services Research, 19(1), 170.

Abuosi, A., \& Atinga, R. (2013). Service quality in healthcare institutions: establishing the gaps for policy action. International Journal of Health Care Quality Assurance, 26(5), 481-492. 
Al-Borie, H. \& Damanhouri, A. (2013). Patients' satisfaction of service quality in Saudi hospitals: a SERVQUAL analysis. International Journal of Health Care Quality Assurance, 26(1), 20-30.

Al-Farraj, O. (2009). Assessing the quality of healthcare services in higher education hospitals in Syria from the patient's perspective Damascus University. Journal for Economic and Legal Sciences, 25(2), 53-93.

Al-Hawary, S., Alghanim, S., \& Mohammad, A. (2011). Quality level of health care service provided by King Abdullah educational hospital from patient's viewpoint. Interdisciplinary Journal of Contemporary Research in Business, 2(11), 552-572.

AlRyalat, S. A., Ahmad, W., \& Abu-Abeeleh, M. (2019). Factors affecting patient's satisfaction in outpatient clinics in Jordan: cross-sectional study. Journal of Hospital Management and Health Policy, 3(2), 1-6.

Al-Tit, A. (2015). The effect of service and food quality on customer satisfaction and hence customer retention. Asian Social Science, 11(23), 129-139.

Al-Zubaidi, G.D., \& Hassan, R. A. M. (2010). The relationship between formal and central and their impact on the quality of health services. Journal of Baghdad College of Economic Sciences University, 24, 107--144.

Amin, M., \& Nasharuddin, S. (2013). Hospital service quality and its effects on patient satisfaction and behavioural intention. Clinical Governance: An International Journal, 18(3), 238-254.

Ampah, I. T., \& Ali, R. S. (2019). Measuring patients (customers) perceptions and expectations of service quality in public healthcare institutions: Servqual model. International Journal of Economics \& Business, 5(1), 6-17

Asif, M., Jameel, A., Sahito, N., Hwang, J., Hussain, A., \& Manzoor, F. (2019). Can leadership enhance patient satisfaction? Assessing the role of administrative and medical quality. International journal of environmental research and public health, 16(17), 3212.

Asif, M., Jameel, A., Sahito, N., Hwang, J., Hussain, A., \& Manzoor, F. (2019). Can leadership enhance patient satisfaction? Assessing the role of administrative and medical quality. International journal of environmental research and public health, 16(17), 3212.

Atinga, R., Abekah-Nkrumah, G., \& Domfeh, K. (2011). Managing healthcare quality in Ghana: a necessity of patient Satisfaction. International Journal of Health Care Quality Assurance, 24(7), 548-563.

Badri, M., Attia, S., \& Ustadi, A. (2009). Healthcare quality moderators of patient satisfaction: testing for causality. International Journal of Health Care Quality Assurance, 22(4), 382-410.

Bahadori, A., Hajibabaee, F., Ashghali Farahani, M., \& Peyrovi, H. (2016). The relationship between nursing leadership and patient satisfaction. International Journal of Medical Resource Health Science, 5, 134-141.

Boadi, E. B., Wenxin, W., Bentum-Micah, G., \& Jerry, I. K. (2019). Impact of Service Quality on Customer Satisfaction in Ghana hospitals: A PLS-SEM Approach. Canadian Journal of Applied Science and Technology, 7(3), 503-511.

Chahal, H., \& Mehta, S. (2013). Modeling patient satisfaction construct in the Indian health care context. International Journal of Pharmaceutical and Healthcare Marketing, 7(1), 75-92.

Choi, K., Lee, H., Kim, C. \& Lee, S. (2005). The service quality dimensions and patient satisfaction relationships in South Korea: comparisons across gender, age and types of service. Journal of Services Marketing, 19(3), 140-149.

Cohen, J. B., Myckatyn, T. M., \& Brandt, K. (2017). The importance of patient satisfaction: a blessing, a curse, or simply irrelevant?. Plastic and reconstructive surgery, 139(1), 257-261.

Dahlsrud, A. (2008). How corporate social responsibility is defined: an analysis of 37 definitions. Corporate Social Responsibility and Environmental Management, 15(1), 1-13.

Diab, S. M. (2012). Measuring the dimensions of the quality of medical services provided in Jordanian government hospitals from the perspective of patients and employees. Journal of the Islamic University for Economic and Administrative Studies, 20(1), 69-104.

Elleuch, A. (2008). Patient satisfaction in Japan. International Journal of Health Care Quality Assurance, 21(7), $692-705$.

Farahani, M. F., Shamsikhani, S., \& Hezaveh, M. S. (2014). Patient satisfaction with nursing and medical care in hospitals affiliated to arak university of medical sciences in 2009. Nursing and Midwifery Studies, 3(3), 10-2.

Farooq, M. S., Salam, M., Fayolle, A., Jaafar, N., \& Ayupp, K. (2018). Impact of service quality on customer satisfaction in Malaysia airlines: A PLS-SEM approach. Journal of Air Transport Management, 67(September 2017), 169-180.

Fatima, T., Malik, S. A., \& Shabbir, A. (2018). Hospital healthcare service quality, patient satisfaction and loyalty: An investigation in context of private healthcare systems. International Journal of Quality and Reliability Management, 35(6), $1195-1214$.

Ganasegeran, K., Perianayagam, W., Abdul Manaf, R., Jadoo, A., Ahmed, S., \& Al-Dubai, S. A. R. (2015). Patient satisfaction in Malaysia's busiest outpatient medical care. The Scientific World Journal, 19(5), 1-7.

Gronroos, C. (1984). The perceived service quality concept - a mistake? Managing Service Quality, 11(3), $150-152$.

Hemadeh, R., Hammoud, R., Kdouh, O., Jaber, T., \& Ammar, L. (2019). Patient satisfaction with primary healthcare services in Lebanon. The International Journal of Health Planning and Management, 34(1), 423-435.

Huerta, T. R., Harle, C. A., Ford, E. W., Diana, M. L., \& Menachemi, N. (2016). Measuring patient satisfaction's relationship to hospital cost efficiency: can administrators make a difference?. Health Care Management Review, 41(1), 56-63.

Ikediashi, D., Ogunlana, S. and Odesola, I. (2015). Service quality and user satisfaction of outsourced facilities management (FM) services in Nigeria's public hospitals. Built Environment Project and Asset Management, 5(4), 363-379.

Jabnoun, N. and AL Rasasi, A. (2005). Transformational leadership and service quality in UAE hospitals. Managing Service Quality, 15(1), 70-81. 
Jamaluddin, J., \& Ruswanti, E. (2017). Impact of service quality and customer satisfaction on customer loyalty: A case study in a private Hospital in Indonesia. IOSR Journal of Business and Management, 19(5), 23-33.

Kang, G., \& James, J. (2004). Service quality dimensions: an examination of Grönroos's service quality model. Managing Service Quality, 14(4), 266-277.

Kotler, P. (2014). Marketing Management, $14^{\text {th }}$ ed, Prentice Hall.

Ladhari, R. (2008). Alternative measures of service quality: a review. Managing Service Quality: An International Journal, $18(1), 65-86$.

Louw, J. M., Marcus, T. S., \& Hugo, J. F. (2017). Patient-or person-centred practice in medicine?- A review of concepts. African Journal of Primary Health Care \& Family Medicine, 9(1), 1-7.

Manzoor, F., Wei, L., Hussain, A., Asif, M., \& Shah, S. I. A. (2019). Patient Satisfaction with Health Care Services; An Application of Physician's Behavior as a Moderator. International Journal of Environmental Research and Public Health, 16(18), 3318.

Mohamed, B., \& Azizan, N. A. (2015). Perceived service quality's effect on patient satisfaction and behavioural compliance. International Journal of Health Care Quality Assurance, 28(3), 300-314.

Mosadeghrad, A.M. (2012) A conceptual framework for quality of care. Materia Socio Medica 24(4), $251-261$.

Mulisa, T., Tessema, F., \& Merga, H. (2017). Patients' satisfaction towards radiological service and associated factors in Hawassa University Teaching and referral hospital, Southern Ethiopia. BMC health services research, 17(1), 441.

Munnukka, J., Järvi, P. and Outi, U. (2013). Impact of service quality dimensions on the formation of customer value in B to B services. Marketing Intelligence \& Planning, 31(3), 286-299.

Naidu, A. (2009). Factors affecting patient satisfaction and healthcare quality. International Journal of Health Care Quality Assurance, 22(4), 366-381.

Ogaji, D. (2017). What does quality mean to the patient? An exploration of the expectations of patients for primary health care in Nigeria. The Nigerian Health Journal, 16(4), 230-243.

Pai, Y., \& Chary, S. (2013). Dimensions of hospital service quality: a critical review Perspective of patients from global studies. International Journal of Health Care Quality Assurance, 26(4), 308-340.

Parasuraman, A., Zeithaml, V. \& Berry, L. (1988). SERVQUAL: a multiple item scale for measuring consumer perception of service quality. Journal of Retailing, 64(1), 12-37.

Rust, R. and Oliver, R. (1994). Service quality: insights and managerial implications from the frontier. In Rust, R.T. \& Oliver, R.L. (Eds), Service quality: New Directions in Theory and Practice, 241-68.

Saghirou, N. (2012). Quality Assessment of Health Services: A Field Study. Master Thesis, University of Haj Lakhdar, Batna, Algeria.

Salaria, M. R., \& Shakeel, M. (2019). Antecedents of patients satisfaction in health care centers: A case study of Islamabad and Rawalpindi. 17, 365-372.

Shabbir, A., Malik, S. A., \& Malik, S. A. (2016). Measuring patients' healthcare service quality perceptions, satisfaction, and loyalty in public and private sector hospitals in Pakistan. International Journal of Quality \& Reliability Management, 33(5), 538-557.

Soomro, M. H., Magsi, M., \& Lahmar, O. (2018). Patient Satisfaction With Health Care Services In Outpatient Department Of A Dental College Hospital In Pakistan. Update Dental College Journal, 8(1), 55-60.

Tam, J. (2007). Linking quality improvement with patient satisfaction: a study of a health service center. Marketing Intelligence \& Planning, 25(7), 732-745.

Vinagre, M. and Neves, J. (2008). The influence of service quality and patients' emotions on satisfaction. International Journal of Health Care Quality Assurance, 21(1), 87-103.

Wei, J., Wang, X. L., Yang, H. B., \& Yang, T. B. (2015). Development of an in-patient satisfaction questionnaire for the Chinese population. PloS one, 10(12), 1-11.

Yousapronpaiboon, K. and William, J. (2013). Measuring hospital out-patient service quality in Thailand. Leadership in Health Services, 26(4), 338-355.

Yuen, K., \& Thai, V. (2015). Service quality and customer satisfaction in liner shipping. International Journal of Quality and Service Sciences, 7(2/3), 170-183.

Zineldin, M. (2006). The quality of health care and patient satisfaction. International Journal of Health Care Quality Assurance, $19(1), 60-92$.

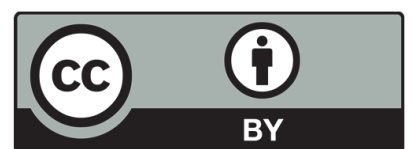

(C) 2020 by the authors; licensee Growing Science, Canada. This is an open access article distributed under the terms and conditions of the Creative Commons Attribution (CC-BY) license (http://creativecommons.org/licenses/by/4.0/). 